\title{
Using Foucault's theory to analyze the relationship between people, organizations, space, power and boundary
}

\author{
Shuaijin Qi* \\ Department of Urban Design, University of Sheffield, Sheffield, South Yorkshire, United Kingdom
}

*Corresponding author: Shuaijin Qi, qsj752942084@163.com

\begin{abstract}
This article will use Foucault's theory to critically consider the relationship between power, people, space and society at the boundary where different powers conflict with each other. Through the analysis of the project "Decolonizing Al Nada," this article will discuss how relations with those with power and social mentality are reframed at the border through the reconstruction of architecture and space.
\end{abstract}

Keywords: Foucault's theory; Power; Boundary; Reconstruction

Publication date: September 2021; Online publication: September 30, 2021

\section{Introduction}

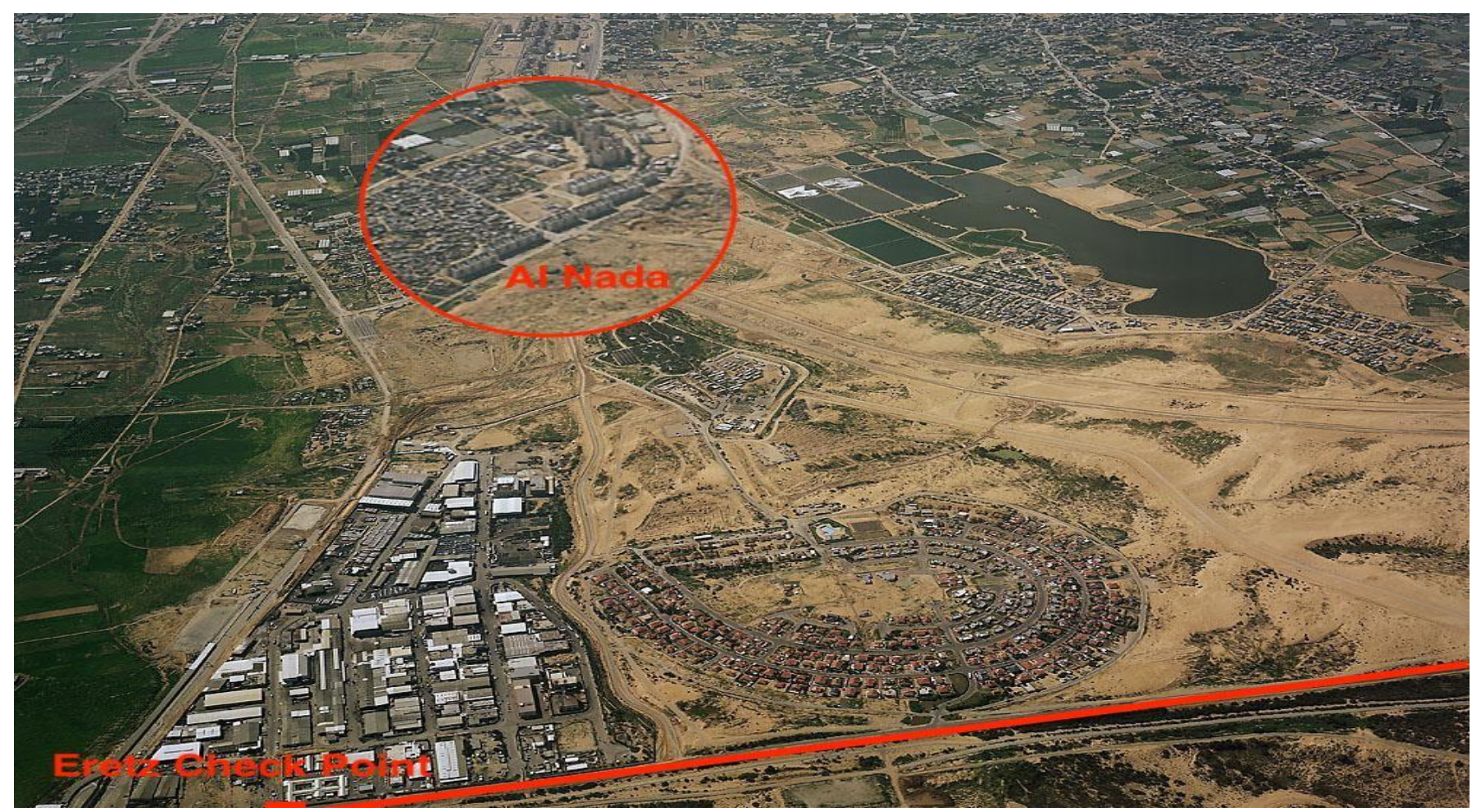

Figure 1. Arial view of Al Nada right before the Israeli colonies demolition of 2008

The project Destruction and Reconstruction is located in Al Nada, the northernmost part of Beit Hanoun, which is on the border of the conflict between the Palestinian and Israeli regimes (see Figure 1.). Here, wars and armed conflicts have caused a large number of refugees to become homeless. This project is a 
social housing project initiated by the government using a top-down approach to resettle Palestinian returnees. The main goal of this project is to reconstruct the residential spaces destroyed during the war, add some new housing units, and renew the infrastructure and public spaces in the city ${ }^{[1]}$. In the process of construction, the designers challenged the power structures of the borders and created a new sense of community for the inhabitants by using architectural and spatial interventions. The following article will use Foucault's theoretical framework to analyze this project in-depth in terms of the two themes of boundary and power and explore how architecture challenges power relations.

\section{Considering Boundary by Using Foucault's Theory}

In Foucault's theory, in order to explain more clearly the operation mode of power, he mentioned the term government. The meaning of the government here not only refers to the political structure or the governance of the nation but also indicates the possible ways of guiding the actions of individuals or organizations, while also suggesting that governance is the construction of the possible limits of the activities of people ${ }^{[2]}$. The area where two fields of action are adjacent to each other forms the boundary, and the boundary is not something that exists naturally; it is a highly architected place that is reproduced by people crossing it and the power that exists on both sides of the boundary can be clearly demonstrated when the subject crosses it $^{[3]}$. For example, at the borders of two countries or regimes, the field of people's behavior and activities is monitored and limited by power. Only with the authorization or approval of the powers on both sides of the border can people cross the border; otherwise, they are considered to cross the border illegally and would be punished by powers.

In the Destruction and Reconstruction project, the Al Nada neighborhood is located at the border between the Israeli and Palestinian regimes, where the Palestinian-Israeli conflict is relatively intense, and where the entire area is not only under blockade, but also at risk of war at any moment. Here, power has become more obvious, and the Palestinian and Israeli regimes have tightened their regulations on the border and the subjects that are in the border area. After the war, the original inhabitants of Beit Hanon became displaced refugees. This area, which was previously Palestinian territory, has now become a border between the two regimes. The spatial manifestation of this change is that the separation wall has replaced some of the temporary dividing lines and created places such as security zones and checkpoints. This area of Beit Hanon has also experienced continuous destruction, expulsion, reconstruction and return during the ongoing war between the two regimes. At this border, Palestinian returnees are a marginalized group, distinct from ordinary citizens, who are simultaneously regulated and restricted by both Palestinian and Israeli authorities. In this project, the construction of the Al Nada community not only provides a shelter for Palestinian returnees but also serves as an expression of opposition to the Israeli colonization of the Palestine Gaza region. At this border, there is an inequality of power relations. In order to protect these returnees from the next attack, these reconstructed buildings need to be protective, but the construction of concrete-reinforced buildings in Gaza puts these refugees at greater risk, as these reinforced shelters become the preferred site for the next Israeli targeting, and the spaces reconstructed to protect these refugees may eventually become the reason for new attacks and destruction. In addition, any ideas for the reconstruction and renovation of refuge spaces must be communicated to the Israeli government, and the relevant materials used in the construction process need to be authorized and approved by the Israeli regime [1]. The Israeli government hopes to strengthen its power through this series of surveillance, management and control tools, while the Palestinian government hopes to oppose the Israeli government's colonization and destruction through this project.

\section{Applying Foucault's Theory to Understand Power}

Foucault's theory mentioned that power is subject less, a relationship, a system of interlocking networks 
inherent in the institution itself. People are not the holders of power but are part of the network of power relations as the tools to operate it ${ }^{[3]}$. In the "Decolonizing Al Nada project," for example, there is also a system of power in the Gaza region in which the Palestinian government, the Israeli government and the refugees are all part of this power relationship. This region has experienced war and strife, and the refugees are constantly moving, but the power relationship is always present, and in the process of destruction and reconstruction, the government wants to strengthen its power and position through colonization, supervision and control. In this power relationship, the refugees seem to be the objects of power implementation, in a marginalized and vulnerable position, but they are also constantly changing the power relationship in the system by constructing a sense of community and coalition.

Power and resistance are coexistent. According to Foucault, where there is power, there is always resistance. Resistance is a form of intransigence and opposition to the relations of control in existing power ${ }^{[4]}$. In border areas, inequalities of race, nationality, and gender produce oppression and also breed resistance [5]. In the "Decolonizing Al Nada project," the Gaza region is at the border of the Palestinian and Israeli regimes. There are multiple resistances within this complex network of power. For example, the Israeli government's war against Palestinian Gaza is a form of dissatisfaction and resistance to the existing power relations, and they want to acquire more land and power through war and colonization. In addition, the designers of the $\mathrm{Al} \mathrm{Nada} \mathrm{complex} \mathrm{also} \mathrm{want} \mathrm{to} \mathrm{resist} \mathrm{Israeli} \mathrm{colonization} \mathrm{by} \mathrm{constructing} \mathrm{a} \mathrm{common} \mathrm{space}$ and sense of community in the process of reconstruction, both of which are not against a particular government, institution or group, but rather to reconstruct the power relations that exist in Gaza. Since the Israeli government considers any public space that can gather more than five people to be a potential threat, in this project the designer wants to transform private spaces into common spaces instead of public spaces, where people can communicate, organize activities and maintain a collective consciousness, and he wants to avoid over-designing these spaces and create a common space that can only exist with people's participation (see Figure 2). This reconstruction breaks down old power relations and reconstructs new alliances. The refugees, who have experienced war, reconstruction and return together, interact and get to know each other in these spaces. These spaces enhance the emotional connection between refugees, bringing a new collective consciousness and reconstructing power relations, changing the old social structure.

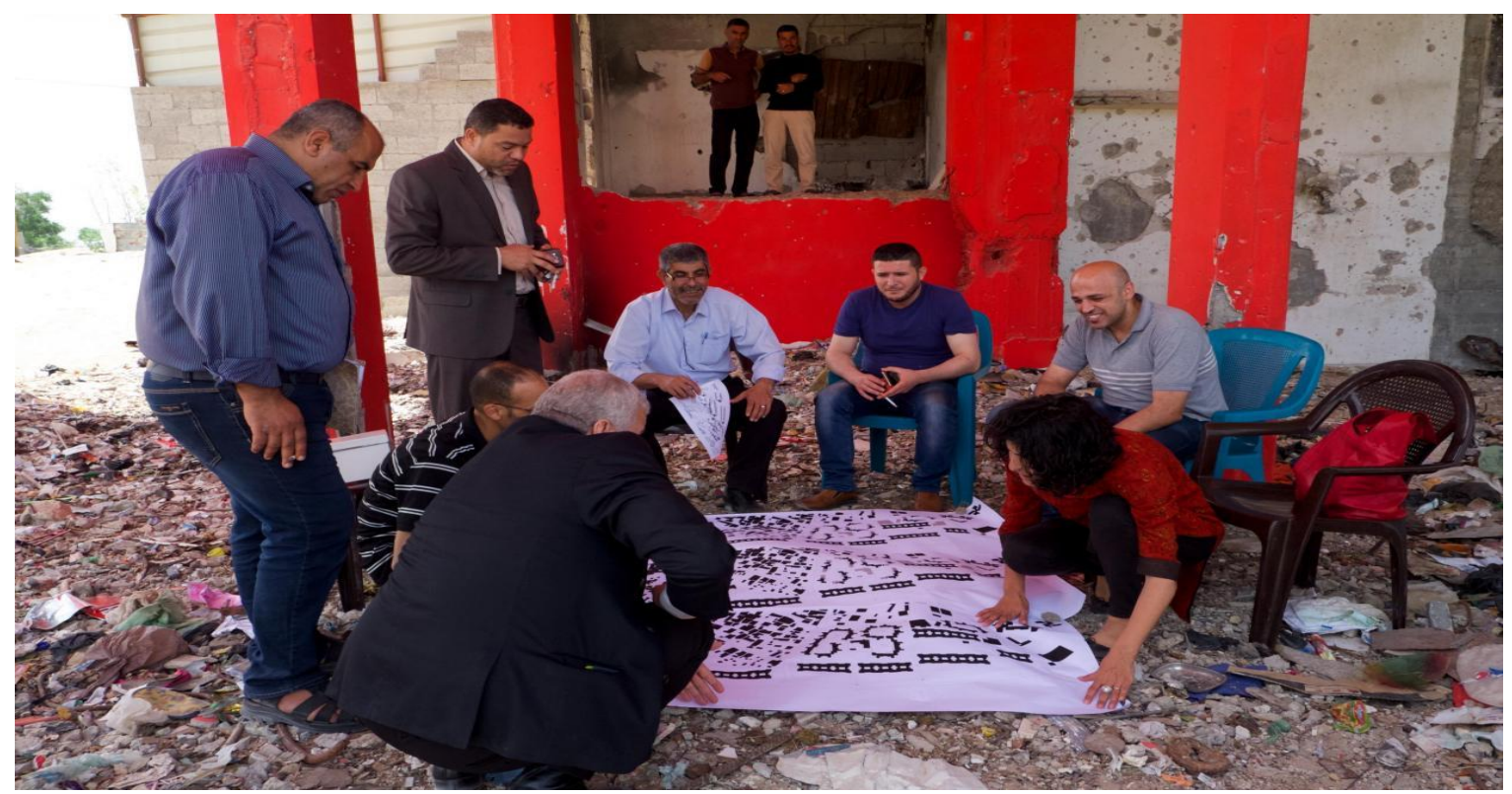

Figure 2. Designing the common space

\section{Conclusion}

Borders are not only places where power can be demonstrated, but also where power is implemented. At 
the borders, conflicts between regimes and religions are more evident and power relations are relatively more complex. In the project "Destruction and Reconstruction," the Gaza region, as a border space, has experienced shifts in power through constant wars and colonization, and at the same time, it has also nurtured resistance. By examining Foucault's theory and analyzing this project, the author recognized the inequality of power systems within the borders of regime and religion and the ability of architectural design to act as a means of intervention to challenge existing power relationships. This intervention can change the social structure and mentality of the inhabitants, creating a sense of community and empowering some marginalized groups. For urban and architectural designers, the process of practice cannot be limited to spatial design but needs to expand the scope of thinking to critically understand the relationship between space, people, power and social structures. In the design process, architects need to take a practical approach, place architecture in social situations and contexts, and think about the relationship between architectural space and existing social contexts from multiple perspectives

\section{Disclosure statement}

The author declares no conflict of interest.

\section{References}

[1] Alessandro P, Beit S, 2016, Israel Al Nada: Destruction and Reconstruction. Available at: http:/www.decolonizing.ps/site/cycles-of-destruction-and-reconstruction/

[2] Biemann U, 2002, Performing the Border: On Gender, Transnational Bodies, and Technology. Globalization on the Line: Culture, Capital, and Citizenship at us Borders, 99-118.

[3] Borden I, Penner B, Rendell J, 2002, Bell Hooks: "Choosing the Margin as a Space of Radical Openness.” In Gender Space Architecture, Routledge, 219-225.

[4] Foucoult M, 1975, Discipline and Punish. A. Sheridan Tr, Paris FR, et al., 1982, The subject and power. Critical Inquiry, 8(4): 777-795.

[5] Foucault M, 1980, Power/Knowledge: Selected Interviews and Other Writings 1972-1977, New York, Pantheon. 